\title{
An intracranial dermoid tumour with large right parietal infarct- A rare case report
}

\author{
Sarkar $\mathrm{S}^{1 *}$, Islam MM${ }^{1}$, Avijit $\mathrm{D}^{2}$, Hossen $\mathrm{MK}^{2}$, Dasgupta $\mathrm{A}^{1}$, Saha $\mathrm{S}^{1}$, Sazib SMF${ }^{1}$, Khan $\mathrm{MN}^{1}$ and Mazumder $\mathrm{U}^{3}$ \\ ${ }^{1}$ Department of Neurosurgery, Shaheed Suhrawardy Medical College, Bangladesh \\ ${ }^{2}$ Bangabandhu Sheikh Mujibur Rahman Medical University, Bangladesh \\ ${ }^{3}$ Dhaka Medical College, Bangladesh
}

\begin{abstract}
Intracranial dermoid tumours arise from inclusion of ectodermally committed cells at the time of closure of the neural groove between the third \& fifth week of embryonic life, and account for $0.04 \%$ to $0.25 \%$ of the all intracranial tumor. Intracranial tumours may rarely present with stroke, which is mostly related to invasion, compression, or encasement of intracranial vessels by the tumour mass. Although dermoid tumours are known to produce a mass effect and occasionally to narrow intracranial vessels, it is very unusual for them to present with sudden ischaemic symptoms. We report the case of a man presenting with convulsion, later revealing a parietal dermoid tumor. To our knowledge, it is very rare in the literature. We discuss here thoroughly the probable mechanism of association of stroke with such an intracranial tumor. Surgical intervention using right parietal craniotomy was approached and complete removal of the tumor was achieved. The patient recovered thereby and histopathological study proved the tumor's type.
\end{abstract}

\section{Introduction}

Intracranial dermoid tumours arise from inclusion of ectodermally committed cells at the time of closure of the neural groove between the third and fifth week of embryonic life, and account for $0.04 \%$ to $0.25 \%$ of the all intracranial tumors [1]. Intracranial tumours may rarely present with stroke, which is mostly related to invasion, compression, or encasement of intracranial vessels by the tumour mass. Although dermoid tumours are known to produce a mass effect and occasionally to narrow intracranial vessels, it is very unusual for them to present with sudden ischaemic symptoms $[2,3]$.

We describe a case of intracranial dermoid tumour associated with infarction in the right parietal area.

\section{Case report}

A 37-year-old, right-handed man presented with chronic headache with epilepsy persisting for the past 5 years. The patient had a history of stroke 8 years back with left sided hemiparesis. On admission, neurological examination revealed mild bilateral papilloedema with left sided hemiparesis. Magnetic Resonance Imaging showed a hyper intense lesion with a large area of hypo intensity on right parietal region on $\mathrm{T}_{1}$ image with slight homogenous enhancement in contrast image suggestive of intracranial dermoid tumour with large infarct (Figure 1). Right parietal craniotomy was done and complete removal
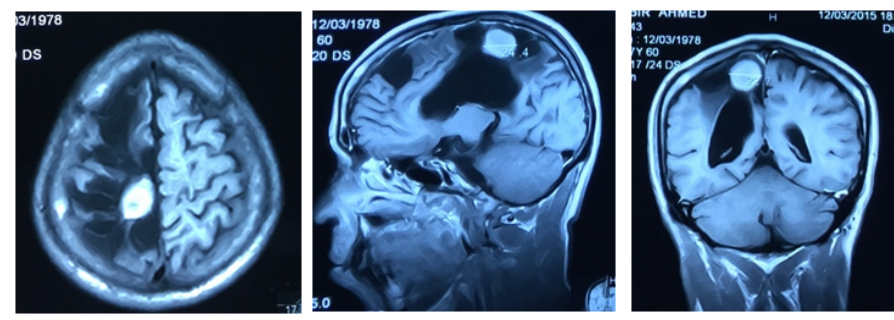

Figure 1. Contrast enhanced MRI of Brain shows intracranial dermoid tumor with large infarct. of the tumor was achieved (Figure 2). The post-operative period was uneventful (Figure 3 and 4). The histopathology report of the excised specimen revealed features of benign intracranial dermoid tumour (Figure 5 and 6).

\section{Discussion}

The authors described an intracranial dermoid tumour that was associated with an ischemic lesion occurred 8 years back. Only one case like this has been published in the world [4].

In our case, the patient had a history of sudden onset of left sided hemiparesis 8 years back but the patient didn't take any conventional treatment as well as brain imaging. When the patient developed

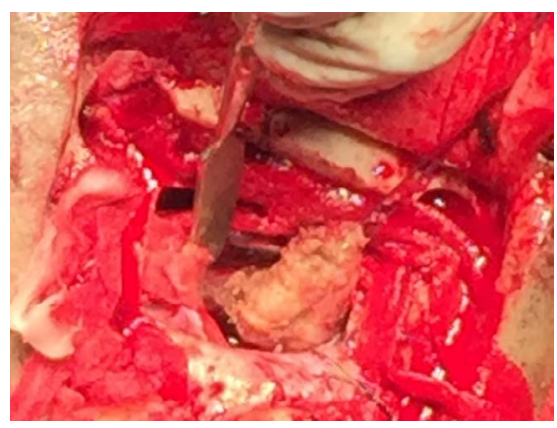

Figure 2. Per operative view of dermoid tumor.

Correspondence to: Sarkar S, Department of Neurosurgery, Shaheed Suhrawardy Medical College, Dhaka Bangladesh, E-mail: saumitra_nsurg@yahoo.com

Key words: dermoid, infarct, intracranial, tumor

Received: December 03, 2016; Accepted: December 26, 2016; Published: December 28, 2016 


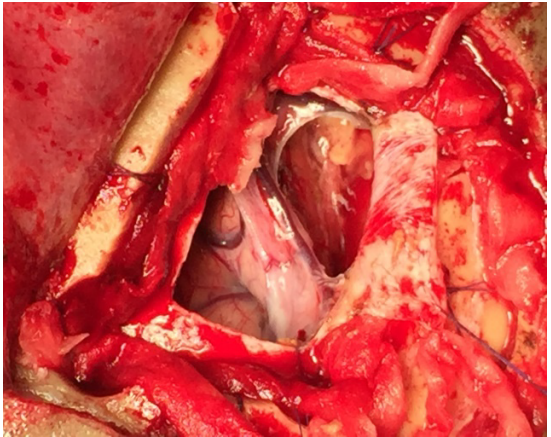

Figure 3. Per operative view after removal.

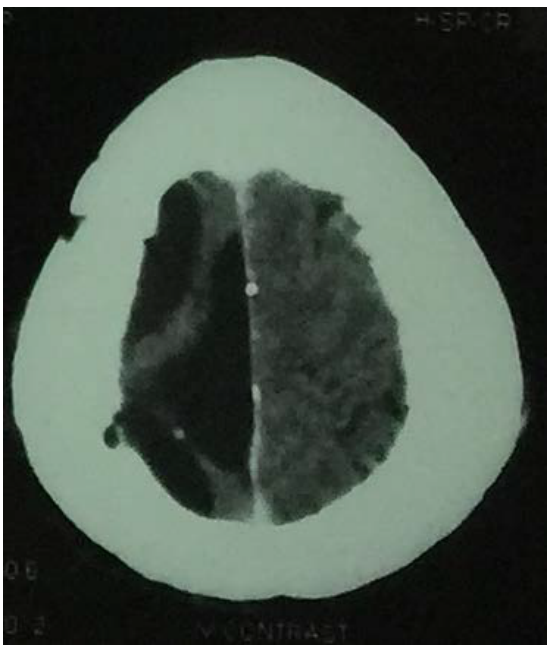

Figure 4. Post-operative CT scan of brain.

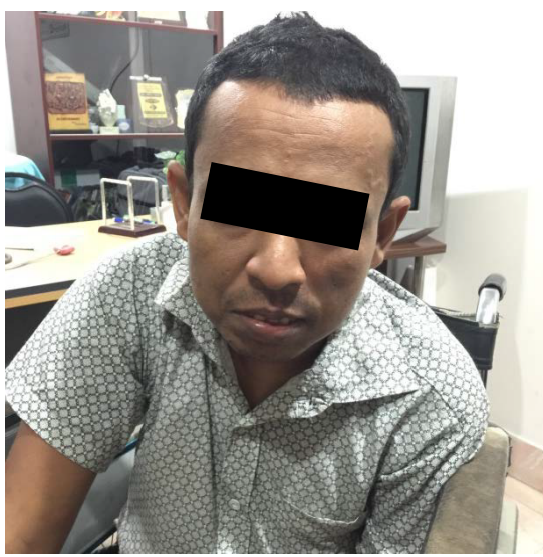

Figure 5. Post-operative status of the patient.

increased intensity of headache and epilepsy, then he was admitted to hospital and an MRI was done. The incidence of intracranial dermoid is a rare entity and the association with stroke is extremely rare.

Civit $\mathrm{T}$ et al. [4] reported a case of a woman presenting with sudden neurological deficit, revealing a parasellar dermoid tumour. To their knowledge, that was the first reported case in the literature.

The pathogenesis of such a tumour being associated with a stroke may be explained as an inflammatory reaction of the cortical vessels those were subjected to stenosis. As suggested for tumors, tumor fragment embolisation - caused by coagulopathy, may be responsible for later occurrence of ischemic stroke [5], such a tumour may follow

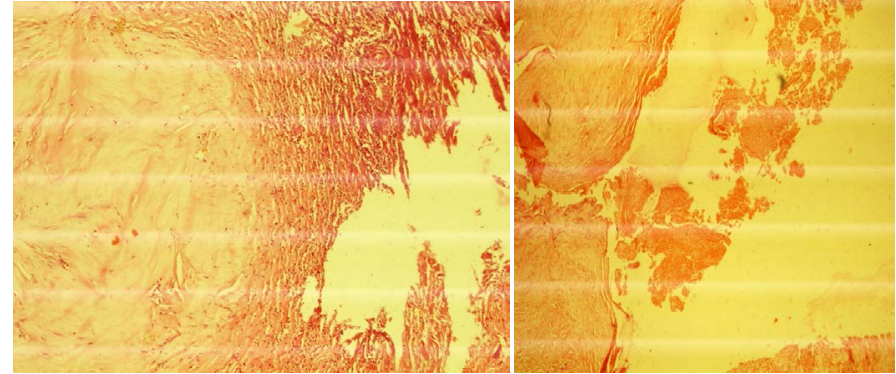

Figure 6. Histopathological findings of the dermoid tumor.

a similar course of pathomechanism. Other mechanisms like direct compression of vessels by the tumour and hyper viscous obstruction of small end vessels as suggested for tumors [6] also may be suggested for such a tumour.

After surveying the literature, we must emphasize the unusual occurrence of dermoid tumour associated with stroke as observed in our case.

\section{References}

1. Philips WE 2nd, Martinez CR, Cahill DW (1994) Ruptured intracranial dermoid tumor secondary to closed head trauma. Computed tomography and magnetic resonance imaging. J Neuroimaging 4: 169-170. [Crossref]

2. Aoki N, Sakai T, Oikawa A, Takizawa T, Koike M (1999) Dissection of the middle cerebral artery caused by invasion of malignant glioma presenting as acute onset of hemiplegia. Acta Neurochir (Wien) 141: 1005-1008. [Crossref]

3. Komotar RJ, Keswani SC, Wityk RJ (2003) Meningioma presenting as stroke: report of two cases and estimation of incidence. J Neurol Neurosurg Psychiatry 74: 136-137. [Crossref]

4. Civit T, Pinelli C, Lescure JP, Anxionnat R, Auque J, et al. (1997) Stroke related to a dermoid cyst: case report. Neurosurgery 41: 1396-1399. [Crossref]

5. Seok JM, Kim SG, Kim JW, Chung CS, Kim GM, et al. (2010) Coagulopathy and embolic signal in cancer patients with ischemic stroke. Ann Neurol 68: 213-219. [Crossref]

6. Dearborn JL, Urrutia VC, Zeiler SR (2014) Stroke and Cancer- A Complicated Relationship. J Neurol Transl Neurosci 2: 1039. [Crossref]

Copyright: (C2016 Sarkar S. This is an open-access article distributed under the terms of the Creative Commons Attribution License, which permits unrestricted use, distribution, and reproduction in any medium, provided the original author and source are credited. 